\title{
Qualitative Behavior of a State-dependent Functional Differential Equation
}

\section{Yin-Wei Lin* and Tzon-Tzer Lu}

Department of Applied Mathematics, National Sun Yat-sen University, Kaohsiung, Taiwan 80424, R.O.C

\begin{abstract}
This paper deals with the state-dependent functional differential equations $x(x(t))$. We give the strict proof of qualitative properties that Eder's case and the solution of the state-dependent differential equation is not unique. In some conditions, we also extend Eder's case.
\end{abstract}

Keywords: State-dependent; Analytic solution; Fixed point; Qualitative behavior

\section{Introduction}

Functional differential equations with delay have long been studied due to their practical applications [1]. For example, early in 1967 Cooke [2] mentioned that some population models and infection models obey the equation

$$
\mathrm{x}^{\prime}(\mathrm{t})+\mathrm{ax}(\mathrm{t}-\mathrm{r}(\mathrm{x}(\mathrm{t})))=0 .
$$

Stephan [3] studied the equation

$$
\mathrm{x}^{\prime}(\mathrm{t})+\mathrm{ax}(\mathrm{t}-\mathrm{h}(\mathrm{t}, \mathrm{x}(\mathrm{t})))=\mathrm{F}(\mathrm{t}),
$$

for some population and infection models. Such type of differential equations with state dependent delay unavoidable contains certain composition of unknown function. In literature they are called the state-dependent delay differential equations (SDDE).

There are many research directions on these equations. For instance, Liu and Keiji et al. [4,5] found the analytic solutions of many such iterative functional differential equations. The existence and uniqueness of solution is one of the major problems. For examples, Dunkel [6] worked on $\mathrm{x}^{\prime}(\mathrm{t})=\mathrm{f}(\mathrm{x}(\mathrm{h}(\mathrm{x}(\mathrm{t}))))$, and Fiagbedzi and Gebeily [7] on

$$
\mathbf{x}^{\prime}(\mathrm{t})=\frac{1}{g(x(x(t)))}
$$

by using Banach or Schauder fixed point theorem. Also great attention had been paid to the qualitative properties of these SDDE. For example, Stanek [8] proved every solution of $\mathrm{x}^{\prime}(\mathrm{t})=\mathrm{x}(\mathrm{x}(\mathrm{t}))+\mathrm{x}(\mathrm{t})$, either vanishes identically or is strictly monotonic. Fusco and Guglielmi [9] discussed a regularization for discontinuous of SDDE. Hu and $\mathrm{Wu}$ [10] developed global Hopf bifurcation theory and got periodic solutions of SDDE. Eder [11] classified all the solutions of $\mathrm{x}^{\prime}(\mathrm{t})=\mathrm{x}(\mathrm{x}(\mathrm{t}))$ as four types. In this paper, more detailed analysis on Eder's work. In fact, two types of the increasing solutions are identical. In some situations, we had surprising non-uniqueness of the solutions.

This paper is organized as follows. We survey Eder's results and list some basic formulas in Section 2. Some new qualitative behaviors are given in Section 3. These two sections contain some rigorous proofs not mentioned in reference [11]. The final section addresses the conclusion and some open problems.

\section{Eder's Results}

Definition 1: A solution of the functional differential equation

$$
\mathrm{x}^{\prime}(\mathrm{t})=\mathrm{x}(\mathrm{x}(\mathrm{t}))
$$

is a $\mathrm{C}^{1}$ function $\mathrm{x}: \mathrm{A} \rightarrow \mathrm{R}$ from an interval $\mathrm{A} \subset \mathrm{R}$.

Remark 1: $\mathrm{x}(\mathrm{x}(\mathrm{t}))$ is not well-defined, since $\mathrm{x}: \mathrm{A} \rightarrow \mathrm{R}$.

Theorem 1: If $\mathrm{x}(\mathrm{t})$ is a solution of state-dependent differential equation $\mathrm{x}^{\prime}(\mathrm{t})=\mathrm{x}(\mathrm{x}(\mathrm{t}))$, then $\mathrm{x}(\mathrm{t})$ is monotonic increasing or decreasing.

Proof: This is a special case of [12] i.e. $\mathrm{x}(\mathrm{t}) \geq 0$ or $\mathrm{x}(\mathrm{t}) \leq 0$ for $\mathrm{x} \in \mathrm{A}$.

Theorem 2: For $\mathrm{x}(\mathrm{t})$ is a solution of state-dependent differential equation of (3) and $x(a)=a$ if

1. $\mathrm{x}^{\prime}(\mathrm{a})>0$, then there is no $\mathrm{c}<\mathrm{a}$ such that $\mathrm{x}^{\prime}(\mathrm{c})=0$ i.e. the solution $\mathrm{x}(\mathrm{t})$ is strictly increasing;

2. $x^{\prime}(a)<0$, then there is no $d>a$ such that $x^{\prime}(d)=0$ i.e. the solution $\mathrm{x}(\mathrm{t})$ is strictly decreasing.

Proof: See Eder [11].

Corollary 3: (Eder, Monotonicity of Solutions)

Let $\mathrm{x}(\mathrm{t})$ be a solution of (3) in an interval A. Then one and only one of the following statements is true:

$$
\begin{aligned}
& \text { 1. } \mathrm{x}^{\prime}(\mathrm{t})=0, \forall \mathrm{t} \in \mathrm{A} ; \\
& \text { 2. } \mathrm{x}^{\prime}(\mathrm{t})>0, \forall \mathrm{t} \in \mathrm{A} ; \\
& \text { 3. } \mathrm{x}^{\prime}(\mathrm{t})<0, \forall \mathrm{t} \in \mathrm{A} .
\end{aligned}
$$

Remark 2: We give the Theorem 1 and 2 because Eder's proof (Lemma 2 [11]) is not strict enough. The lemma 2 has no initial value condition. Theorem 1 only guarantee monotonic $\mathrm{x}(\mathrm{t}) \geq 0$ or $\mathrm{x}(\mathrm{t}) \leq 0$ for $\mathrm{x} \in \mathrm{A}$. But Theorem 2 guarantee "strictly" monotonic; Theorem 1 has no initial value $\mathrm{x}(\mathrm{a})=\mathrm{a}$ condition but Theorem 2 has the initial value condition. Add the initial value condition $\mathrm{x}(\mathrm{a})=\mathrm{a}$ in Corollary 3 , then we have Corollary 4.

Corollary 4: For the initial value problem

*Corresponding author: Yin-Wei Lin, Department of Applied Mathematics, National Sun Yat-sen University, Kaohsiung, Taiwan 80424, R.O.C, E-mail: panguapig@yahoo.com.tw

Received July 18, 2013; Accepted October 15, 2013; Published October 22, 2013

Citation: Lin YW, Lu TT (2013) Qualitative Behavior of a State-dependent Functional Differential Equation. J Appl Computat Math 2: 144. doi:10.4172/21689679.1000144

Copyright: @ 2013 Lin YW, et al. This is an open-access article distributed under the terms of the Creative Commons Attribution License, which permits unrestricted use, distribution, and reproduction in any medium, provided the original author and source are credited. 
$\left\{\begin{array}{l}x^{\prime}(t)=x(x(t)) \\ x(s)=s\end{array}\right.$,

1. If $s>0$, then $x(t)$ is strictly increasing;

2. If $s<0$, then $x(t)$ is strictly decreasing;

3. If $s=0$, then $x(t)$ is a trivial solution for $\forall t \in R$.

Proof: It is easy to prove theorem by using Theorem 2 as $\mathrm{x}(\mathrm{a})=\mathrm{a}$.

Lemma 5: (Eder, The interval of right hand side is finite)

Let $\mathrm{A}=[\mathrm{a}, \mathrm{b}]$ be the domain of $\mathrm{x}(\mathrm{t})$ in case 1 as the above, then $\mathrm{b}<\infty$.

Proof: Supposenot, for $x^{\prime \prime}(t)=x^{\prime}(x(t)) x^{\prime}(t)>0, \exists t t_{1}>0$ such that $x(t)>t+1$ for $\mathrm{t} \geq \mathrm{t}$. So we have $\mathrm{x}(\mathrm{x}(\mathrm{t}))>\mathrm{x}(\mathrm{t}+1)$ and $\mathrm{x}(\mathrm{t}+1)=\mathrm{x}(\mathrm{t})+\mathrm{x}^{\prime}(\mathrm{t})+1 / 2 \mathrm{x}^{\prime}(\xi) \geq$ $\mathrm{x}^{\prime}(\mathrm{t})=\mathrm{x}(\mathrm{x}(\mathrm{t}))>\mathrm{x}(\mathrm{t}+1)$ contradiction.

Remark 3: Lemma 5 is a part of Eder's case 2 in Theorem 2. The proof of Eder is not clear. We rewrite the statement and the proof.

Theorem 6 (Eder, Local Existence and Uniqueness)

Given any $\mathrm{a} \in(-1,1)$, there is a unique real-valued solution $\mathrm{x}(\mathrm{t})$ of (3), $x(a)=a$ on an open neighborhood of $|t-a|<\in$ for small $\in>0$.

Proof: See reference [11].

Theorem 7: (Eder, Classification)

Let $\mathrm{x}:[\mathrm{a}, \mathrm{b}] \rightarrow \mathrm{R}$ be an non-extendable solution of $\mathrm{x}^{\prime}(\mathrm{t})=\mathrm{x}(\mathrm{x}(\mathrm{t}))$. Then one and only one of the following statements is true.

1. $x(t)=0, \forall t \in R: a=-\infty, b=\infty$.

2. $x^{\prime}(\mathrm{t})>0: 0<\mathrm{b}<\infty$ and $\mathrm{x}(\mathrm{b})=\mathrm{b}$,

(a) $0<\mathrm{a}<1<\mathrm{b}$ and $\mathrm{x}(\mathrm{a})=\mathrm{a}$ : $\mathrm{x}$ has two fixed points;

(b) $\mathrm{a}=-\infty,-\infty<\mathrm{x}(-\infty)<0$ and $\mathrm{x}(\mathrm{x}(-\infty))=0$.

3. $\mathrm{x}^{\prime}(\mathrm{t})<0 \forall \mathrm{t}$ :

(a) $-\infty<\mathrm{a}<-1<\mathrm{b}<0$ : $\mathrm{x}(\mathrm{a})=\mathrm{b}: \mathrm{x}(\mathrm{b})=\mathrm{a}$ are 2 -period point;

(b) $\mathrm{a}=-\infty$ and $\mathrm{b}=\infty$ : $\mathrm{x}(-\infty)=\infty,-\infty<\mathrm{x}(\infty)<0$ and $\mathrm{x}(\mathrm{x}(\infty))=0$.

Remark 5: (1) 2(a) are not exist uniqueness because the solution can be extend from left hand side of the fixed point a to $-\infty$, then the solution 2(a) becomes the solution 2(b).

(2) If its fixed point of $x(s)=s<-1$, then case $3 a$ and $3 b$ can be combined. If $-1<\mathrm{s}<0$, case $3 \mathrm{a}$ does not exist.

Because Eder's paper did not tell us how to get these results. We need some Lemmas to prove the theorem in the next section.

\section{Qualitative Properties}

We can discuss the qualitative properties of state-dependent differential equations.

Lemma 8: Suppose $\mathrm{x}(\mathrm{t})$ is a solution of (3) for all $t \in(-\infty, \mathrm{b}]$ and $\mathrm{x}(\mathrm{a})=\mathrm{a}>0$, then we have

(i) $\lim _{t \rightarrow-\infty} x(t)=-A$ for some fixed number $A$;

(ii) $\lim _{\mathrm{t} \rightarrow-\infty} \mathrm{x}^{\prime}(\mathrm{t})=0$;

(iii) $\mathrm{A}>0$.

Proof: (i) Since $x(t)$ is increasing, we have only two cases. Either $\lim _{t \rightarrow-\infty} x(t)=-\infty$ or $\lim _{t \rightarrow-\infty} x(t)=-A$. Assume $\lim _{t \rightarrow-\infty} x(t)=-\infty$, then we have $\lim _{\mathrm{t} \rightarrow-\infty} \mathrm{x}^{\prime}(\mathrm{t})=\lim \mathrm{t} \rightarrow-\infty \mathrm{x}(\mathrm{x}(\mathrm{t}))=\mathrm{x}(-\infty)=-\infty<0$ contradicts to $\mathrm{x}(\mathrm{t})$ has increasing properties in Lemma 1.

(ii) Because lims $\rightarrow-\infty \mathrm{x}(\mathrm{s})=-\mathrm{A}$, we have $|\mathrm{x}(\mathrm{s})+\mathrm{A}|<\frac{\varepsilon}{2}$ for given $\varepsilon>0$, let $\mathrm{s}<\min \left\{\mathrm{a}-1, \mathrm{a}-2\left(\frac{A+a}{\varepsilon}\right), a+2\left(\frac{A+a}{\varepsilon}\right)\right\}$,

$$
\text { For } \mathrm{s}<\mathrm{a}-2\left(\frac{A+a}{\varepsilon}\right) \Rightarrow \mathrm{s}-\mathrm{a}<-2\left(\frac{A+a}{\varepsilon}\right)
$$

For $\mathrm{s}-\mathrm{a}<0$, we have $-\left(\frac{A+a}{s-a}\right)<\frac{\varepsilon}{2}$

For $\mathrm{s}<\mathrm{a}+2\left(\frac{A+a}{\varepsilon}\right) \Rightarrow \mathrm{s}-\mathrm{a}<2\left(\frac{A+a}{\varepsilon}\right)$

For $\mathrm{s}-\mathrm{a}<0$, we have $\left(\frac{A+a}{s-a}\right)<\frac{\varepsilon}{2} \quad(5) \Rightarrow-\left(\frac{A+a}{s-a}\right)>-\frac{\varepsilon}{2}$

By (4) and (5), then we have $\left|\frac{-A-a}{s-a}\right|<\frac{\varepsilon}{2}$ and $\mathrm{t} \in$ (s, a) $\left|x^{\prime}(t)\right|=\left|\frac{x(s)-x(a)}{s-a}\right| \leq\left|\frac{x(s)+A}{s-a}\right|+\left|\frac{-A-a}{s-a}\right|<\varepsilon$

(iii) For $x(t)$ is increasing, we have $x(-A) \geq \lim _{t \rightarrow-\infty} x(t)=-A$. So we have

$0=\lim _{t \rightarrow \infty} \mathrm{x}^{\prime}(\mathrm{t})=\lim _{t \rightarrow \infty} \mathrm{x}(\mathrm{x}(\mathrm{t}))=\mathrm{x}\left(\lim _{t \rightarrow \infty} \mathrm{x}(\mathrm{t})\right)=\mathrm{x}(-\mathrm{A}) \geq-\mathrm{A}$

Lemma 9 Suppose $\mathrm{x}(\mathrm{t})$ is a solution of (3) for all $\mathrm{t} \in(-\infty, \infty)$ and $\mathrm{x}(\mathrm{s})=\mathrm{s}<0$, then we have

(i) $\mathrm{x}^{\prime}(\mathrm{t})<0$ and $\mathrm{x}^{\prime}(\mathrm{t})>0$;

(ii) $\lim _{\mathrm{t} \rightarrow-\infty} \mathrm{x}(\mathrm{t})=\infty$;

(iii) $\lim _{t \rightarrow \infty} x(t)=B$ for some bounded number $B$;

(iv) $\lim _{\mathrm{t} \rightarrow \infty} \mathrm{x}^{\prime}(\mathrm{t})=0$.

Proof: (i) $x(t)<0$ because Lemma 2 in Section 2 and $x^{\prime \prime}(t)<0$ because $\mathrm{x}^{\prime \prime}(\mathrm{t})=\mathrm{x}^{\prime}(\mathrm{x}(\mathrm{t})) \mathrm{x}^{\prime}(\mathrm{t})>0$.

(ii) For $\mathrm{x}^{\prime}(\mathrm{t})$ is nonnegative, we have $\mathrm{x}(\mathrm{t}) \geq \mathrm{x}(\mathrm{p})+\mathrm{x}^{\prime}(\mathrm{p})(\mathrm{t}-\mathrm{p})$. Let $\mathrm{p}<\mathrm{s}$.

Because $\mathrm{x}(\mathrm{t})$ is increasing, we have $\mathrm{x}^{\prime}(\mathrm{p})<\mathrm{x}^{\prime}(\mathrm{s})=\mathrm{s} \Rightarrow \mathrm{x}^{\prime}(\mathrm{p})(-1)>-\mathrm{s}$; Similarly we have

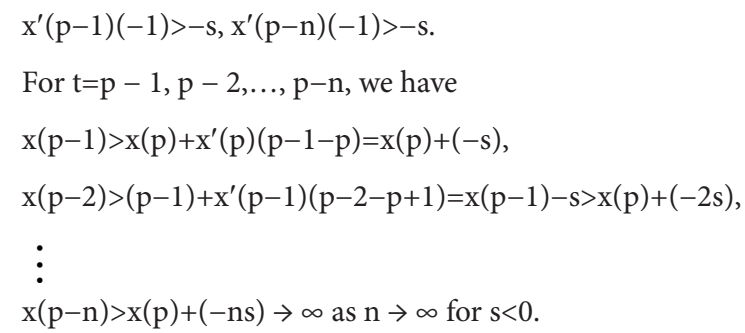

(iii) For (ii) and $\mathrm{x}(\mathrm{s})=\mathrm{s}<0, \exists e$ such that $\mathrm{x}(\mathrm{e})=0$ by I.V.T. Because $\mathrm{t}<e$ and $x(t)$ is decreasing, we have $x(t) \geq x(e)=0$. If $x(t)$ is not bounded, then we have $N>0$ and $p<e$ such that $x(t)=p$ as $t \geq N$. For $x(t)$ is decreasing, we have $x^{\prime}(t)=x(x(t))=x(p) \geq x(e)=0$ for $t \geq N$. This is impossible because $\mathrm{x}^{\prime}(\mathrm{t})<0$.

(iv) Let $\mathrm{N}=\max \left\{\mathrm{s}+1, \mathrm{~s}+\frac{2}{\varepsilon}(\mathrm{s}-\mathrm{B})\right\}$. Because $\lim _{\mathrm{t} \rightarrow \infty} \mathrm{x}(\mathrm{t})=\mathrm{B}$, we have

$|\mathrm{x}(\mathrm{h})-\mathrm{B}|<\lim _{\mathrm{t} \rightarrow \infty} \mathrm{x}(\mathrm{t})=\frac{\varepsilon}{2}$ for given $\varepsilon>0$ as $\mathrm{h} \geq \mathrm{N} \geq \mathrm{s}+1$. For $\mathrm{h}-\mathrm{s} \geq 1$ and $\mathrm{h} \geq \mathrm{s}+\frac{2}{\varepsilon}(\mathrm{s}-\mathrm{B})$, we have $\left|\frac{x(h)-B}{h-s}\right|<\frac{\varepsilon}{2}$ and $\frac{s-B}{h-s}<\frac{\varepsilon}{2}$. So we have 
$\left|\frac{x(s)-s}{h-s}\right| \leq\left|\frac{x(h)-B}{h-s}\right|+\left|\frac{B-s}{h-s}\right|<\varepsilon$

Theorem 10: For $\mathrm{x}(\mathrm{t})$ is a solution of $\left\{\begin{array}{l}x^{\prime}(t)=x(x(t)) \\ x(a)=a\end{array}, 0<\mathrm{a} \leq 1\right.$ and $\mathrm{z}(\mathrm{t})$ is a solution of $\left\{\begin{array}{l}z^{\prime}(t)=z(z(t)) \\ z\left(a^{\prime}\right)=a^{\prime}\end{array}, 0<\mathrm{a}^{\prime} \leq 1\right.$. If $\mathrm{a} \neq \mathrm{a}^{\prime}$, then it is impossible for $x(t)$ intersect $z(t)$ for $\max \left\{a, a^{\prime}\right\}$, i.e. the solution of $\left\{\begin{array}{l}x^{\prime}(t)=x(x(t)) \\ x(a)=b\end{array}\right.$, is unique for $\mathrm{t}>\max \left\{\mathrm{a}, \mathrm{a}^{\prime}\right\}$.

Proof: Without losing generosity, let $\mathrm{a}<\mathrm{a}^{\prime}$. If $\mathrm{x}(\mathrm{t})$ intersect $\mathrm{z}(\mathrm{t})$ for the first time at $(\mathrm{c}, \mathrm{p})$, then we have $\mathrm{x}(\mathrm{c})=\mathrm{z}(\mathrm{c})=\mathrm{p}<\mathrm{c}$ and $\mathrm{x}(\mathrm{t})<\mathrm{z}(\mathrm{t})$ for $\mathrm{t}<\mathrm{c}$. We claim the following statements.

(i) $\mathrm{x}^{\prime}(\mathrm{c}) \geq \mathrm{z}^{\prime}(\mathrm{c})$;

(ii) $\mathrm{x}(\mathrm{p})<\mathrm{z}(\mathrm{p})$, then substituting state-dependent differential equation, we have $\mathrm{x}^{\prime}(\mathrm{c})=\mathrm{x}(\mathrm{x}(\mathrm{c}))=\mathrm{x}(\mathrm{p})<\mathrm{z}(\mathrm{p})=\mathrm{z}(\mathrm{z}(\mathrm{c}))=\mathrm{z}(\mathrm{z}(\mathrm{c}))=\mathrm{z}^{\prime}(\mathrm{c})$ contradict to (i).

Back to the proof of $\mathrm{i}$ ) For $\mathrm{x}(\mathrm{t})$ and $\mathrm{z}(\mathrm{t})$ are increasing and concave up, we have $x(c+h)>z(c+h)$ and $x(c-h)<z(c-h)$. Then we have

$x^{\prime}(c)=\lim _{h \rightarrow 0} \frac{x(c+h)-x(c-h)}{h}>\lim _{h \rightarrow 0} \frac{z(c+h)-z(c-h)}{h}=z^{\prime}(c)$

(ii) If $\mathrm{x}(\mathrm{t})$ intersect $\mathrm{z}(\mathrm{t})$ for the first time at $(\mathrm{c}, \mathrm{p})$, then we have $\mathrm{x}(\mathrm{c})=\mathrm{z}(\mathrm{c})=\mathrm{p}<\mathrm{c}$ and $\mathrm{x}(\mathrm{p})<\mathrm{z}(\mathrm{p})$ for $\mathrm{p}<\mathrm{c}$.

Theorem 11: For these state-dependent differential equations $\left\{\begin{array}{l}x^{\prime}(t)=x(x(t)) \\ x(a)=a\end{array}\right.$ and $\left\{\begin{array}{l}y^{\prime}(t)=y(y(t)) \\ y(a)=b\end{array}, \quad \mathrm{x}(\mathrm{t})\right.$ must intersect $\mathrm{y}(\mathrm{t})$ for $\mathrm{t}<\min \{\mathrm{a}, \mathrm{b}\}$, i.e. the solution of $\left\{\begin{array}{l}x^{\prime}(t)=x(x(t)) \\ x(a)=b\end{array}\right.$ is not unique for $\mathrm{t}<\min \{\mathrm{a}, \mathrm{b}\}$.

Proof: Suppose $\lim _{t \rightarrow-\infty} x(t)=-A$ and $\lim _{t \rightarrow-\infty} y(t)=-B$. By the Lemma 1(ii) in Section 3, we have

$$
0=\lim _{t \rightarrow \infty} \mathrm{x}^{\prime}(\mathrm{t})=\lim _{t \rightarrow \infty} \mathrm{x}(\mathrm{x}(\mathrm{t}))=\mathrm{x}\left(\lim _{t \rightarrow \infty} \mathrm{x}(\mathrm{t})\right)=\mathrm{x}(-\mathrm{A}) .
$$

Lemma 12: Similarly $y(-B)=0$. For $A \leq B, x(t)$ must intersect $y(t)$. Suppose $A>B, x(t)$ is not intersect with $y(t)$, then we have $y(t)<x(t)$ for all $\mathrm{t}<\mathrm{a}$. So we have $-\mathrm{B}=\lim _{\mathrm{t} \rightarrow-\infty} \mathrm{y}(\mathrm{t})<\lim _{\mathrm{t} \rightarrow-\infty} \mathrm{x}(\mathrm{t})=-\mathrm{A}$ contradiction.

Remark 6: Suppose $(\alpha, \beta)$ is the intersection point of is the intersection point of $x(t)$ and $y(t)$, then the solution of the initial value problem $x^{\prime}(t)=x(x(t))$, with $x(\alpha)=\beta$ is not unique for $\alpha \neq \beta$, but the solution is unique as $\alpha=\beta$.

\section{Conclusions}

For the decreasing solution of (3), the proof of case 3 in (Eder, Classification) has not been finished. Maybe we need some other techniques or tools to finished it. And we suppose the solution of (3) exists throughout this paper. Actually, we need to establish the global existence and uniqueness theorem for all the cases. Furthermore, we hope these techniques can be used to extend other cases of statedependent differential equations.

\section{References}

1. Hale JK (1987) Theory of Functional Differential Equations. Spring-Verlag, New York.

2. Cooke KL (1967) Functional differential system: some models and perturbation problems. International Symposium on Differential Equations and Dynamical Systems, held in puerto Rico, Academic Press, New York 167-183.

3. Stephan $B H(1969)$ On the existence of periodic solutions of $z^{\prime}(t)=-a z(t-r+k \mu(t$ $\mathrm{z}(\mathrm{t})))+\mathrm{F}(\mathrm{t})$. J Differ Equ 6: 408-419.

4. Liu T, Li H (2008) Local analytic solution of a second-order functional differential equation with a state derivative dependent delay. Appl Math Comput 197: 158166.

5. Keiji W (1984) Control of systems with time-delay in the state variables. III. Functional-analytic approaches. (Japanese) Special issue on control of time delay systems. Systems and Control 28: 309-317.

6. Dunkel GM (1970) On nested functional differential equations. SIAM J Appl Math 18: 514-525.

7. Fiagbedzi YA, El-Gebeily MA (2000) Existence and uniqueness of the solution of a class of nonlinear functional differential equations. Ann of Diff Eqs 16: 381390.

8. Stanek S (1995) On global properties of solutions of functional differential equation $x^{\prime}(t)=x(x(t))+x(t)$, Dynamic Sys Appl 4 263-278.

9. Fusco G, Guglielmi N (2011) A regularization for discontinuous differential equations with application to state-dependent delay differential equations of neutral type. J Differential Equations 250: 3230-3279.

10. Hu QW, Wu JH (2010) Global continua of rapidly oscillating periodic solutions of state-dependent delay differential equations. J Dynam Differential Equations 22: 253-284.

11. Eder $E(1984)$ The functional differential equation $x^{\prime}(t)=x(x(t))$. J Differ Equ 54 $390-400$.

12. Wu H (1999) On existences and asymptotic behaviors of strong solutions of equation $x^{\prime}(t)=f(x(x(t))$. Ann of Diff Eqs 9: 336-351. 